\title{
A CONSTRUÇÃO DA PAZ NO AFEGANISTÃO: UMA ANÁLISE DOS LIMITES DE UMA PAZ HÍBRIDA
}

\author{
Devlin Biezus ${ }^{1}$
}

\begin{abstract}
Resumo
O presente artigo propõe analisar a construção da paz no Afeganistão. O objetivo do trabalho é demonstrar como as relações entre elite local e agentes internacionais da operação da paz modificam ou subvertem a agenda da paz liberal da construção da paz. Para isso, emprega-se o conceito da paz híbrida para analisar as esferas securitárias e políticas da construção de paz. O argumento da pesquisa é a de que o local como compreendido pelos atores internacionais não possui uma autonomia, de fato, na condução do processo de construção da paz. A metodologia adotada é a qualitativa e as técnicas utilizadas são a análise documental de fontes primárias e secundárias e o desenvolvimento do estudo de caso. $\mathrm{O}$ caso da construção da paz no Afeganistão permitiu a problematização do entendimento de paz presente nesse caso. Esse entendimento pode ser problematizado em dois principais pontos. Primeiro, o discurso da autonomia afegã perante a construção da paz não se reflete na realidade. Em segundo lugar, o local compreendido pelos atores internacionais, no caso do Afeganistão, é formado a partir das perspectivas e interesses internacionais. O estudo proposto no presente trabalho se insere no debate das problemáticas encontradas no processo de construção da paz. A perspectiva híbrida contribui com o debate de que o processo de paz deve ser analisado de forma multidimensional, demonstrando a interação entre atores locais e internacionais. O estudo também colabora com o debate mais amplo na área dos estudos para a paz, pois trata de problemáticas epistemológicas trazidas pelos projetos de construção da paz, como a da paz liberal, da normalização do Estados perante a sociedade internacional e do consenso do argumento da paz liberal.
\end{abstract}

Palavras-Chave: Construção da paz; Paz híbrida; Afeganistão.

\section{INTRODUÇÃO}

A invasão ao Afeganistão, em 2001, foi a resposta imediata às ações terroristas da Al Qaeda à Nova Iorque e Washington D.C. Seu objetivo foi retirar o grupo Talibã do governo afegão - responsável por permitir o abrigo e treinamento da Al Qaeda no território do Afeganistão. Após a invasão e o desmantelamento do Talibã do governo, seguiu-se o processo de construção da paz. O presente artigo analisa criticamente esse processo de construção da paz. A ênfase do estudo está na compreensão das interações entre os atores internacionais, que desenham o projeto internacional de paz, e os atores locais, mais precisamente a elite política afegã. Tal análise dialoga, intimamente, com uma literatura que aborda a problemática do local na

\footnotetext{
${ }^{1}$ Mestre em Ciência Política pelo Programa de pós-graduação em Ciência Política da UFPR. devlinbiezus@gmail.com. https://orcid.org/0000-0003-1479-457X
} 
construção da paz e faz parte do que se pode denominar uma "virada local" dentro dos Estudos para a Paz². Dentro desse enquadramento, o enfoque das análises está na crítica da falta da participação de agentes locais na construção da paz, argumentando que o local possui a capacidade para construir um ambiente estável pósconflito violento (GOMES, 2013, p. 63). Por exemplo, Roger Mac Ginty (2010; 2011) emprega o conceito do hibridismo e da paz híbrida para demonstrar as distorções sofridas pelo projeto de construção da paz quando este interage com a realidade e atores locais (MAC GINTY, 2010; 2011). Segundo Mac Ginty (2011), a paz híbrida é formada por meio do encontro entre a condução impositiva de um processo de construção da paz e uma resistência local. Assim, a construção da paz passa por modificações ao longo de sua aplicabilidade devido às influências das ações de atores locais. Esses atores seriam capazes de apresentar alternativas à paz liberal, seja ignorando, resistindo ou subvertendo esse processo (MAC GINTY, 2011).

Tendo isso em conta, neste artigo argumenta-se que o local como compreendido pelos atores internacionais não é capaz de representar os interesses e necessidades da sociedade afegã perante a construção da paz. Esse argumento parte do contexto de uma literatura crítica sobre a construção da paz a qual compreende que essas operações não refletiriam as reais necessidades de uma sociedade civil pós-conflito. Para evidenciar esse argumento, o artigo analisa as interações entre atores internacionais e locais nos âmbitos políticos e de segurança da construção da paz.

De modo a avançar com a sua análise, este artigo utiliza-se de uma metodologia qualitativa, nomeadamente a análise crítica de fontes primárias e secundárias, além do estudo de caso. O Afeganistão foi escolhido como estudo de caso devido à ênfase dada pelas Nações Unidas sobre a necessidade de os atores afegãos serem autônomos para conduzir a construção da paz (S/2001/1154, p. 2). Para desenvolver o argumento da pesquisa, o artigo está estruturado em duas seções. A primeira seção aborda a perspectiva teórica da paz híbrida, apresentando sua conceitualização. A segunda seção analisa a construção de paz no Afeganistão, utilizando o conceito da paz híbrida como uma lente analítica para compreender esse processo. Esse artigo se insere no debate das problemáticas encontradas no processo de construção da paz. A perspectiva da paz híbrida contribui com o debate de que o processo de paz deve ser analisado de forma multidimensional, demonstrando a interação entre atores locais e internacionais.

\section{O CONCEITO DA PAZ HÍBRIDA NOS ESTUDOS DA CONSTRUÇÃO DA PAZ}

No contexto da literatura dos estudos para a paz, a virada local problematiza como os agentes locais e os valores locais são percebidos pelas operações de construção da paz internacionais (LEDERACH, 1997; SPIVAK, 2010; RICHMOND, 2010; MASCHIETTO, 2016; TOLEDO; FACCHINI, 2017). Entre as

\footnotetext{
${ }^{2}$ Para uma literatura sobre a virada local nos estudos sobre a paz, ver Leonardsson e Rudd (2015); Maschietto (2016), Mac Ginty e Richmond (2016), e Toledo e Facchini (2017).
} 
perspectivas analíticas da virada local, está o conceito do hibridismo e da paz híbrida. Esse conceito busca analisar a dinâmica local ao interagir com os atores internacionais da construção da paz (GOMES, 2013, p. $68)$.

Nesse sentido, o debate relacionado à paz híbrida constitui uma importante contribuição para a literatura da virada local e para as críticas da construção da paz (MASCHIETTO, 2016, p. 520). De maneira a analisar os usos do hibridismo pela literatura dos estudos para a paz, Mac Ginty e Richmond (2016) delineiam o hibridismo como um conceito dinâmico e que, portanto, não reflete uma reação estática entre atores locais e internacionais. Ao entender o hibridismo como um processo fluido, os autores argumentam que uma intervenção de construção da paz nunca seria total porque existiriam lacunas em que a agência local poderia operar. É a partir desse contexto, do dinamismo do conceito de hibridismo, que os autores definem a paz híbrida. Assim, a paz híbrida seria a tradução, a acomodação ou o equilíbrio encontrado entre atores internacionais e o local na construção da paz (MAC GINTY; RICHMOND, 2016, p. 11). Ainda, os autores reconhecem que há dois tipos de paz híbrida, sendo essas a negativa e a positiva. Por um lado, a paz híbrida positiva envolveria uma resolução gradual dos dilemas que circulam as relações de poder existentes, principalmente em relação àqueles em posições marginais. Isso significa que as tensões entre normas internacionais e práticas culturais, históricas e identitárias deveriam ser resolvidas e não ignoradas (MAC GINTY; RICHMOND, 2016, p. 12). Por outro lado, se tais tensões forem ignoradas, o resultado seria uma paz híbrida negativa, formada por formas de política híbridas as quais reificam as estruturas e hierarquias existentes de poder (MAC GINTY; RICHMOND, 2016, p. 12).

Por sua vez, Mac Ginty (2011) argumenta que a paz híbrida representa uma análise que vai além dos binários da construção da paz ocidental e sua recepção pelo não-Ocidental. Por isso, o autor entende a paz híbrida como uma forma de crítica à construção da paz que busca compreender como a paz liberal é transformada ao enfrentar a situação real de um país pós-conflito (MAC GINTY, 2010) ${ }^{3}$. Esse conceito é operacionalizado por Mac Ginty (2011) por meio de quatro eixos de análise que ilustram a paz híbrida: 1) a habilidade dos agentes internacionais em forçar a aceitação do projeto da paz liberal; 2) a habilidade dos agentes internacionais para incentivar o engajamento local com o projeto da paz liberal; 3) a habilidade dos atores locais em ignorar, subverter ou resistir a paz liberal; 4) a habilidade dos atores locais em realizar alternativas ao projeto da paz liberal (MAC GINTY, 2011; TOLEDO; FACCHINI, 2017). O objetivo de Mac Ginty (2011) ao desenvolver esse modelo é visualizar os principais eixos em que a paz híbrida poderia se concretizar. Esse modelo conceitual fornece os pontos de contatos entre atores internacionais e locais para a possibilidade de analise empírica de cada um desses elementos. Contudo, é necessário ressaltar que o modelo

\footnotetext{
${ }^{3}$ A paz liberal representa um entendimento sobre a construção da paz baseado na democratização, no Estado de direito, na proteção dos direitos humanos e na promoção de uma liberalização econômica nos países pós-conflitos (GOMES, 2013, p. 48). Para mais sobre a paz liberal, ver: David Chandler (2004); Mac Ginty (2011); Gomes (2013); Kemer, Pereira e Blanco (2016).
} 
representa uma abstração do que é possível captar na realidade, não conseguindo captar toda a complexidade e dinamismo das respostas locais à construção da paz (TOLEDO; FACCHINI, 2017, p. 166).

O primeiro eixo de análise - a habilidade dos agentes internacionais em impor a paz liberal - consiste em mecanismos que encorajam conformidade e evitam desvios do projeto liberal de paz. Esses mecanismos são traduzidos pelo poder de aceitação da paz liberal e podem ser apresentados pelo poder de aceitação econômico e também militar. Em relação ao poder de aceitação econômico, por exemplo, a economia de mercado, o incentivo fiscal e a cooptação de agentes locais por meio de incentivos políticos e econômicos são maneiras que os agentes da paz liberal conseguem impor uma possível aceitação de seu projeto (MAC GINTY, 2011, p. 78). Por sua vez, a habilidade de impor a paz liberal por meios militares pode ser operacionalizado em sua forma extrema pelas operações militares, como no caso da ex-Iugoslávia, do Afeganistão e do Iraque. Além da violência direta, a imposição de sanções e a ameaça do uso da força também é uma forma do poder de aceitação da paz liberal (MAC GINTY, 2011, p. 78).

O segundo eixo de análise é a habilidade de incentivar os atores locais com o projeto liberal de paz (MAC GINTY, 2010, p. 400). O autor descreve essa habilidade como o uso dos recursos financeiros internacionais, que são capazes de influenciar a cooperação com parte dos atores locais. Mac Ginty (2011, p. 80) considera que o poder de incentivo é operacionalizado em conjunto com os mecanismos coercitivos tratados anteriormente. Para ilustrar essa dualidade da paz liberal, Mac Ginty utiliza o exemplo das tropas do Canadá que dispararam mais de 4,7 milhões de balas na invasão do Afeganistão em um período de 12 meses, na metade da década de 2000. Ao mesmo tempo, o Afeganistão foi o maior destinatário da assistência internacional canadense, abrangendo investimentos na democratização, governança, desenvolvimento econômico e rural, infraestrutura, educação, saúde, atividades contra narcóticas, desativação de minas terrestres e treinamento policial e militar (MAC GINTY, 2011, p. 81). Dessa forma, o objetivo dos recursos financeiros, como Mac Ginty afirma (2011, p. 83), é disponibilizar investimentos em troca da cooperação local ao programa de construção da paz. A nível estatal, esses recursos financeiros podem tomar forma de empréstimos, assistência ou subsídios. Por exemplo, fundos para a reconstrução de infraestruturas e instituições (MAC GINTY, 2011, p. 82). Ao trazer o eixo analítico do incentivo à paz liberal, Mac Ginty (2011) enfatiza o papel da economia política na construção da paz. O papel dos recursos financeiros externos destinados à construção da paz faz com que atores como partidos políticos, organizações não-governamentais e indivíduos se engajem com atividades que apoiem, ou ao menos não se opõem, à paz liberal em troca de recursos financeiros (MAC GINTY, 2011, p. 83).

O terceiro eixo analítico é descrito por Mac Ginty $(2010 ; 2011)$ como a habilidade de atores locais em resistir, ignorar ou adaptar a intervenção da paz liberal (MAC GINTY, 2010, p. 402). Por atores locais, o autor entende como governo nacional, as municipalidades, partidos políticos, grupos militantes, Organizações nãoGovernamentais, sociedade civil, empresários, comunidades e indivíduos (MAG GINTY, 2011, p. 82). Segundo Mac Ginty, o objetivo desse eixo analítico é considerar a extensão de opções de ação disponíveis ao 
local. Portanto, considerando que os atores locais não são passivos frente à construção da paz ou que aguardam a assistência internacional para serem empoderados (MAC GINTY, 2011, p. 84). Dessa forma, a habilidade de resistir ou subverter a paz liberal está relacionada com o grau de poder de cada ator local, com o grau de dependência entre governo local e atores externos, o grau de quantidade de modificações realizadas nas instituições locais durante o processo de construção da paz e o grau em que os atores locais conseguem mobilizar seus recursos (MAC GINTY, 2010, p. 402). Em suma, esse eixo analítico busca se opor ao entendimento de que após a construção da paz, os atores locais iriam aceitar a os sistemas de tutela internacional e replicar o modelo ocidental da paz liberal sem reinterpretações provenientes do cotidiano local. Segundo Mac Ginty, "em muitos casos isso não ocorre e sistemas de governança local, patronagem e clientelismo iram se misturar com sistemas promovidos por atores internacionais para produzir um [sistema] híbrido" (MAC GINTY, 2011, p. 86) ${ }^{4}$.

Por fim, o quarto eixo analítico se refere à habilidade dos atores locais em conduzir alternativas à forma da paz liberal (MAC GINTY, 2010, p. 403). Essas alternativas, segundo Mac Ginty, ocorrem em espaços políticos, sociais culturais ou econômicos não ocupados pela paz liberal. $\mathrm{O}$ autor argumenta que isso ocorre devido a tendência da paz liberal em enfatizar níveis macro de segurança, política e econômica. Nesse sentido, à nível micro, sendo esse na sociedade e individual, os efeitos da paz liberal são diluídos, na perspectiva de Mac Ginty (2011, p. 87). Nesse sentido, os atores locais seriam capazes de formar alternativas à paz liberal nos espaços à margem das esferas centrais à paz liberal (MAC GINTY, 2011, p. 87). O autor evidencia esse eixo utilizando o exemplo do caso da atuação do Hezbollah no Líbano. O autor argumenta que a habilidade dos atores locais em conduzir alternativas à paz liberal reside em espaços de não engajamento direto com os atores internacionais (MAC GINTY, 2011, p. 88). Na próxima seção, o modelo de Mac Ginty (2011) será utilizado como lente analítica para a construção da paz no Afeganistão.

\section{A CONSTRUÇÃO DA PAZ E A PAZ HÍBRIDA: AS INTERAÇÕES ENTRE INTERNACIONAL E LOCAL NAS ESFEAS POLÍTICA E DE SEGURANÇA}

O objetivo dessa seção é analisar a construção da paz no Afeganistão a partir da perspectiva da paz híbrida. Dessa maneira, é utilizado o modelo de análise de Roger Mac Ginty (2011) para demonstrar como o processo internacional de construção da paz passa por modificações ao longo de sua aplicabilidade devido às influências e interações com as ações dos atores locais. Esses atores seriam capazes de apresentar

\footnotetext{
${ }^{4}$ Tradução livre da autora. No original: "In many cases this is not feasible and local systems of governance, patron- age, and clientelism will mix with internationally sponsored systems to produce a hybrid" (MAC GINTY, 2011, p. 86).
} 
alternativas à paz liberal, seja ignorando, resistindo ou subvertendo esse processo (MAC GINTY, 2011, p. 73). Nesse sentido, o objetivo de uma perspectiva híbrida é demonstrar as contradições que o projeto liberal de construção da paz enfrenta ao encontrar o pragmatismo requerido ao atuar em uma realidade pós-conflito (MAG GINRTY, 2011, p. 91).

Essa seção se divide em duas subseções: a primeira subseção discute a esfera política e a segunda discute a esfera securitária da construção da paz. A justificativa da análise dessas esferas está na importância dada a reconstrução das instituições políticas no Afeganistão e ao entendimento de que a segurança seria basilar para o desenvolvimento de qualquer empreitada referente à construção da paz (A/56/681S/2001/1157, p. 14). Cada seção demonstrará: a) a habilidade dos agentes internacionais em forçar a aceitação do projeto da paz liberal e também de incentivar a participação local com o projeto da paz liberal; e b) a habilidade dos atores locais em ignorar, subverter ou resistir a paz liberal e realizar alternativas ao projeto da paz liberal (MAC GINTY, 2011; TOLEDO; FACCHINI, 2017).

\subsection{A INSTITUCIONALIZAÇÃO DA CONSTRUÇÃO DA PAZ E DEMOCRATIZAÇÃO: A ESFERA POLÍTICA AFEGÃ}

O planejamento inicial sobre a reestruturação do Afeganistão foi acordado na Conferência de Bonn, em dezembro de 2001. O Acordo foi assinado pelos membros da comunidade internacional e líderes afegãos e estabeleceu quais seriam as autoridades interinas do país após a invasão estadunidense, além de instituir a Força Internacional de Assistência para Segurança (ISAF) no país - nesse período ainda sobre a liderança das Nações Unidas. Primeiramente, o Acordo de Bonn (S/2001/1154, p. 3) criou uma autoridade interina no Afeganistão que após a aprovação do corpo administrativo pela Loya Jirga ${ }^{5}$ foi denominado como Administração Transitória. A Loya Jirga apontou Hamid Karzai como presidente do Afeganistão e noventa e seis ministros e deputados, além dos demais membros que formariam a Administração Transitória do país autoridades que ficariam no poder até a realização de eleições (WARDAK; HAMIDZADA, 2012, p. 80).

O contato inicial entre atores internacionais e locais no contexto pós-atentados de onze de setembro se deu pela aliança entre os Estados Unidos e a Aliança do Norte. Em outubro de 2001, os Estados Unidos lançaram a Operação Enduring Freedom como resposta aos ataques em Nova Iorque e Washington D.C. Com o objetivo de remover o grupo Talibã do poder, os Estados Unidos se aliaram à Aliança do Norte, grupo guerrilheiro que já lutava contra o Talibã no país. Com a saída do Talibã em novembro de 2001, os Estados Unidos concederam à Aliança do Norte o poder político no Afeganistão (JARSTAD; OLSSON, 2012, p. 107). Isso se torna evidente durante a Conferência de Bonn, em que diferentes facções da Aliança do Norte foram direcionadas para posições governamentais (S/2001/1154).

\footnotetext{
${ }^{5}$ A Loya Jirga, ou Grande Conselho, é uma antiga instituição afegã para as resoluções de conflitos e reúne anciões de diferentes etnias e tribos e líderes religiosos (SAIKAL, 2002).
} 
A partir da relação com a Aliança do Norte, pode-se argumentar que os Estados Unidos buscaram dar legitimidade ao projeto internacional de construção da paz tanto internacionalmente quanto perante a população afegã por meio da promoção de uma prática tradicional referente a tomada de decisões (JARSTAD; OLSSON, 2012, p. 110). A tentativa da criação de uma legitimidade da construção da paz foi materializada pelas convocações das Loya Jirgas e pelas eleições democráticas. Em suma, a Loya Jirga pode ser traduzida como Grande Conselho e faz referência a uma prática tradicional para a tomada de decisões e resolução de conflitos composta por diferentes líderes tribais e religiosos. A operacionalização da Loya Jirga pode ser problematizada por ela ser um mecanismo restrito a etnia pashtun, assim, não representando a totalidade das etnias que compõem o Afeganistão. Ainda, a convocação de uma Loya Jirga foi rara durante a história do Afeganistão. Entre 1915 e 1977, a Loya Jirga foi convocada sete vezes. Os objetivos dessas convocações eram endossar reformas políticas e buscar consentimentos em tempo de crise, como endossar a neutralidade do país durante as duas guerras mundiais (LOYN, 2019). Após 2001, a Loya Jirga foi convocada quatro vezes. Entre suas ações, está a aprovação da Administração Transitória, a seleção dos membros da comissão constitucional, a discussão de uma possível negociação com o Talibã e a discussão sobre a não permissão de tropas remanescentes da OTAN no país após 2014. O intuito dos atores internacionais ao promoverem a Loya Jirga era demonstrar como a institucionalização no Afeganistão seria conduzida pelos próprios afegãos, seguindo tradições do país (LOYN, 2019, p. 17).

A institucionalização do novo governo afegão, projetada pelo Acordo de Bonn e respaldada pelas convocações das Loya Jirgas, pode ser entendido como uma maneira em que os atores internacionais buscaram para forçar a aceitação do projeto internacional de construção de paz tanto no âmbito interno quanto externo. A coalizão com a Aliança do Norte e a utilização de mecanismos tradicionais teve como objetivo obter uma legitimidade à intervenção no Afeganistão (KARLBORG, 2013, p. 149).

Apesar dos atores internacionais interpretarem a democratização como um mecanismo de garantir legitimidade local à construção de paz, sua influência no processo eleitoral e na constituição do sistema eleitoral foi significativa na reconstrução das instituições afegãs. Uma das principais características constitucionais que influencia diretamente nas eleições é a centralização do Estado (MALEY, 2018, p. 111). As reações internas sobre essa centralização são diversas. Entre os grupos pashtuns, o grupo étnico majoritário do país, a ideia da centralização foi recebida com bons olhos porque isso resultaria em uma oportunidade de se prevalecerem em relação aos demais grupos étnicos, além de evitar uma fragmentação territorial. Por outro lado, as demais minorias étnicas encararam a centralização como uma tentativa de retomada da dominância pashtun no Afeganistão (MALEY, 2018, p. 111).

Questões como a centralização governamental e o sistema presidencialista, representaram os interesses dos Estados Unidos para o país. O embaixador dos Estados Unidos no Afeganistão, Zalmay Khalilzad, pressionou as Nações Unidas para que o sistema eleitoral vigente no país fosse o Voto Único não Transferível (GOMES, 2018, p. 7). A escolha do sistema presidencialista também ressoa sobre as relações entre os atores 
internacionais e a Aliança do Norte. Argumenta-se que uma presidência forte favoreceria o grupo político de Hamid Karzai e evitaria o surgimento de partidos políticos fortes que exacerbaria as divisões étnicas no país (GOMES, 2018, p. 6).

Ao mesmo tempo em que atores internacionais buscam impor a agenda da paz liberal perante o local, os atores locais também demonstram capacidade de modificar ou subverter essa agenda. Um exemplo de como isso acontece no âmbito político é tratado por Áureo Gomes (2018). O autor associa as literaturas dos estudos eleitorais e da paz híbrida com o intuito de analisar as dinâmicas da competição política (GOMES, 2018, p. 4). Por isso, analisa-se o impacto que o desenho constitucional das eleições afegãs exerce sobre a política do país, a elite política e o eleitorado. Em suma, os aspectos institucionais do sistema eleitoral afegão promovem a fragmentação e o fortalecimento do poder executivo. Isso acontece devido às características do sistema eleitoral, que favorecem a competição individual e o voto personalista. Por isso, os membros do parlamento são intimamente ligados com a província que os elegeram e é esperado que eles forneçam recursos para essas províncias.

Essa prática resulta na fragmentação da sociedade e no individualismo, pois as províncias passam a competir para eleger seus candidatos, além de dificultar a formação de coalizões que fortaleça a câmara legislativa (GOMES, 2018, p. 12). Contudo, os atores locais são capazes de contornar a problemática relativa à formação de coalizões legislativas por meio da organização de votação em bloco. A votação em bloco acontece quando um grupo apoia um único candidato que represente seu distrito. Outras maneiras que grupos locais subvertem características do sistema eleitoral é por meio da determinação do número de candidatos de determinada comunidade iram concorrer às eleições e pela negociação em relação a quem o grupo deve apoiar (GOMES, 2018, p. 8).

Um segundo exemplo das consequências práticas do sistema eleitoral afegão são as interações entre grupos armados que utilizam das eleições democráticas para se legitimarem. Em 2005 - as primeiras eleições parlamentares - das 249 cadeiras disponíveis, 90 candidatos eleitos eram comandantes paramilitares ou associados a algum líder paramilitar (AMAN, 2013, p. 236). Esse dado ilustra como os atores afegãos legitimaram suas posições no governo e influenciaram as prioridades do projeto da construção da paz (AMAN, 2013, p. 236). A questão das lideranças paramilitares é recorrente na literatura sobre o processo de construção da paz no Afeganistão, sendo analisada a partir das questões do patrimonialismo e clientelismo que se formam a partir das relações dos líderes paramilitares com o governo e com sua base de apoio (LISTER, 2007; SHARAN, 2011; MEHRAN, 2018). Essas questões também são estudadas a partir da problemática da ameaça que o fracasso da desmobilização desses grupos apresenta para o monopólico da força coercitiva do governo afegão (MAC GINTY, 2011). Nesse sentido, facções rivais que garantem um lugar no governo criam uma fricção dentro das instituições. Por exemplo, o antigo Ministro da Defesa, Abdul Rahim Wardak, e o antigo Chefe do Estado-Maior, Bismillah Khan, pertenciam aos grupos paramilitares Pashtun e Tadjique, respectivamente. Assim, criando uma rivalidade interministerial no governo (AMAN, 2013, p. 239). 
A partir desse contexto, é possível analisar o cenário que propicia o desenvolvimento das relações clientelistas e interpretá-las como uma maneira em que atores locais cooptam o projeto de construção de paz para seu autobenefício. Segundo Timor Sharan (2011, p. 1110), a institucionalização do Acordo de Bonn e a invasão dos Estados Unidos no Afeganistão resultaram em uma competição entre elites as quais controlavam os ministérios de segurança, possuindo um forte poder em suas províncias, e as elites tecnocratas que representavam os interesses internacionais para a construção de um aparato estatal profissional. A problemática dessa análise tem como ponto de partida a natureza da estrutura de autoridade no Afeganistão.

Nesse caso, há uma dificuldade do poder central em exercer controle nos territórios periféricos. Os poderes provinciais, tribalismo e demais favoritismos étnicos e regionais criam um ambiente em que a força central precisaria se adaptar a essas estruturas para exercer seu poder. Devido a isso, Karzai criou uma política de acomodação para desenvolver uma rede de relações entre antigos líderes tribais, comandantes e outros detentores de poderes locais. A formação de uma rede clientelista foi uma maneira que Hamid Karzai lidou com a ameaça da insubmissão dos detentores de poder nas províncias em relação ao Estado central. Para isso, Karzai ofereceu posições dentro do Estado para lideranças locais e antigos comandantes paramilitares (MALEY, 2018, p. 138).

A partir desses exemplos, é possível interpretar que as instituições formais promovidas pela paz liberal, construídas a partir do financiamento estrangeiro, se tornaram um instrumento de manipulação das redes políticas, usando as capacidades de coerção e administração para legitimar suas ações e fortalecer sua influência no Estado (SHARAN, 2013, p. 347). Compreender a maneira como os atores locais interagem com seu sistema eleitoral permite entendermos as particularidades da democratização afegã.

\subsection{A ISAF, O GOVERNO AFEGÃO E COMANDANTES PARAMILITARES: A INTERAÇÃO ENTRE INTERNACIONAL E LOCAL NA ESFERA SECURITÁRIA}

Nessa subseção, a interação entre atores locais e atores internacionais é problematizada por meio da análise das relações das milícias paramilitares com a operação da Força Internacional de Assistência para Segurança (ISAF), liderada pela Organização do Tratado do Atlântico Norte (OTAN).

Em 2003, a questão de segurança no país começou a se deteriorar devido às insurgências do grupo Talibã. Por isso, a OTAN passou a comandar a ISAF. A partir disso, a participação ativa dos Estados Unidos também aumentou (SUHRKE; HARPVIKEN; STRAND, 2004, p. 6). A OTAN liderou a ISAF a partir de 2003, sendo finalizada em 2014. A Organização foi autorizada pelo Conselho de Segurança das Nações Unidas para atuar no Afeganistão e seu objetivo central foi 
desenvolver novas forças de segurança afegãs e capacitar o governo do Afeganistão em fornecer uma segurança eficaz em todo o país (OTAN, 2015). Em seu ápice, a ISAF contou com uma força formada por mais de 130 mil pessoas e 51 nações como parceiras. No início da operação, suas forças eram direcionadas para a segurança da capital Cabul. A partir de 2006, a operação se expandiu para todo o país (OTAN, 2015).

A política externa estadunidense para o Afeganistão sofreu uma mudança drástica entre 2001 e 2003. O início do processo de construção da paz no país foi caracterizado pelo desejo internacional de deixar poucos expatriados no país, focando na ideia de que os atores locais seriam os responsáveis para conduzir esse projeto (CHESTERMAN, 2002, p. 39). Em 2002, o secretário de defesa estadunidense, Donald Rumsfeld, recebeu relatórios sobre a situação do desenvolvimento do processo de construção da paz no Afeganistão. Os relatórios indicavam que a política dos EUA para o país estava falhando devido à volta dos antigos comandantes paramilitares ao poder. Em seu discurso oficial, o objetivo dos Estados Unidos no Afeganistão seria instalar um regime político democrático no país e combater o terrorismo, o tráfico e cultivo de drogas no país (GAO-05-742, 2005, p. 8).

Esse cenário resultou em uma mudança do posicionamento dos EUA para seus esforços na construção da paz. Em 2003, o presidente Bush apresentou uma nova política denominada Accelerating Success em que aumentava os recursos financeiros para o Afeganistão. As Nações Unidas consentiram e também reproduziram a mudança de posicionamentos dos Estados Unidos para o Afeganistão. Isso pode ser evidenciado com a aprovação da Resolução do Conselho de Segurança 1510 (S/RES/1510, 2003) em que enfatizou a importância de expandir o controle governamental para todo território afegão e aprovou a expansão da ISAF para além de Cabul. Em 2009, a administração de Barack Obama também anunciou uma expansão de soldados estadunidenses para o Afeganistão.

O aumento de soldados foi acompanhado pelo aumento financeiro dos recursos dos Estados Unidos ao país. Entre 2001 e 2002, o Departamento de Defesa dos Estados Unidos destinaram 2 bilhões de dólares para o Afeganistão. Em 2005, esse valor aumentou para 17,2 bilhões. No final de 2012, o Departamento de Defesa solicitou 107,3 bilhões de dólares para os esforços da reconstrução afegã (DODGE, 2013, p. 1204). Esses recursos foram majoritariamente destinados à reconstrução da força coercitiva do Estado. Mac Ginty (2011) considera a quantidade de financiamento destinado à reconstrução da paz como um meio de incentivo dos atores internacionais em engajar os atores locais com o projeto liberal de paz. De acordo com o Banco Mundial, em 2011, era estimado que 97\% do produto interno bruto do Afeganistão derivava de gastos relacionados à presença militar internacional (KERRY, 2011, p. 2). Essa porcentagem demostra uma insustentabilidade desses recursos pelo 
Estado do Afeganistão. Isso é evidenciada na Estratégia de Desenvolvimento Nacional de 2006. No documento, afirma-se que a comunidade internacional importou modelos de forças de segurança demasiados caros que impõem custos ao Afeganistão os quais o governo não seria capaz de sustentar por meio de seus recursos financeiros internos (AFEGANISTÃO, 2006, p. 27).

A abordagem securitária desenvolvida pela OTAN e financiada principalmente pelos Estados Unidos foi alvo de críticas. Um dos argumentos é que a força afegã treinada pela organização internacional não trazia proteção no cotidiano da população, já que o foco da proteção era no governo (FRITZ, 2011, p. 5). Nesse sentido, a segurança foi priorizada como um elemento dos esforços de guerra e não operacionalizada como uma forma de estabilização das comunidades (FRITZ, 2011, p. 5). Essa prática pode ser evidenciada pelos gastos dos Estados Unidos para o Afeganistão durante sete anos. Entre os anos de 2002 e 2009, os Estados Unidos gastaram mais de 21 bilhões de dólares para o desenvolvimento do exército nacional afegão e da força policial. Em contraste, o país disponibilizou cerca de 2,5 bilhões de dólares para as iniciativas das áreas do Estado de direito, democracia e governança (FRITZ, 2011, p. 5).

Para além da questão de financiamento, as relações entre atores internacionais e locais também pode ser analisada a partir da dinâmica entre a ISAF e os detentores de poder locais paraestatais. Critica-se que a heterogeneidade étnica não teria sido refletida no planejamento da atuação da ISAF no país. Van der Lijn argumenta que a ISAF se baseou em uma visão simplista do ambiente político e securitário do Afeganistão. Essa visão teria como base a percepção de que a falta de um Estado aos moldes weberianos criaria um ambiente totalmente anárquico e territórios que não possuiriam qualquer forma de governo. Dessa forma, o projeto da ISAF ignorou as instituições de governo paralelas criadas durante as décadas de conflito (VAN DER LIJN, 2016, p. 161).

Nesse sentido, a ISAF escolheu cooperar com detentores de poder locais paramilitares. O objetivo da ISAF era cooptar esses paramilitares por meio de incentivos financeiros para garantir a segurança da região (VAN DER LIJN, 2016, p. 162). Contudo, isso resultou no rearmamento desses grupos. De maneira paradoxal, a cooperação da ISAF com comandantes paramilitares produz resultados contraditórios aos ideais da paz liberal. A relação entre esses dois atores é estudada por Philipp Münch e Alex Veit (2017). Para os autores, os detentores de poder a nível provincial são denominados como intermediários locais para a intervenção internacional. Esses intermediários são definidos como atores locais que são necessários para que a intervenção internacional alcance seus fins na esfera local. Eles seriam necessários devido a possibilidade de fornecer recursos a intervenção, como informação, proteção e apoio da comunidade (MÜNCH; VEIT, 2017, p. 5). 
A relação de interdependência entre atores internacionais da ISAF e comandantes locais pode ser evidenciada a partir das ações de contingência da ISAF, formada por soldados alemães, que lideraram esforços dos Times de Reconstrução Provinciais (TRPs) nas províncias de Kunduz e de Badakhshan, ambas ao norte do Afeganistão. Münch e Veit (2017, p. 8) identificam as Forças Militares Afegãs (FMA) como intermediários da ISAF. As FMA foram a coalização de grupos armados que lutaram contra o Talibã e se aliaram aos EUA após a invasão de 2001. Depois do início do empreendimento da construção da paz, o grupo foi gradualmente realocado para o exército nacional (MÜNCH; VEIT, 2017, p. 8).

Apesar de serem o público alvo da reintegração para o exército nacional, alguns dos comandantes da FMA mantiveram suas próprias forças armadas. As tropas da ISAF não forçaram o desarmamento porque reconheciam que dependiam dessas forças para assegurar apoio local (MÜNCH; VEIT, 2017, p. 12-13). Como consequência, a atuação da ISAF não mudou as estruturas de poder locais, contribuindo com a dificuldade do governo central em manter o controle dessas províncias (MÜNCH; VEIT, 2017, p. 14).

A partir desse contexto, é possível observar as contradições das ações da ISAF em relação ao projeto da paz liberal. Para a ISAF, foi mais vantajoso assegurar o apoio dos detentores de poder local do que, na prática, apoiar a consolidação do monopólio da força pelo governo central. Analisar a interação entre ISAF e detentores de poder local demonstra as contradições do projeto internacional da construção da paz. Ao analisar essas contradições é possível compreender que alguns objetivos da paz liberal são perseguidos pelos atores internacionais, como eleições livres, construção de instituições e formação de uma força nacional. Contudo, analisar as interações permite que se observe o caminho percorrido da tentativa de alcançar esses objetivos, que no caso da ISAF e dos TRPs se desvirtuam dos valores da paz liberal e se aproximam do pragmatismo militar.

As adaptações pragmáticas que cooptam as elites locais também podem ser observadas a nível da criação da Política Local Afegã (PLA) (SCHMEIDL; MISZAK, 2017, p. 1). A PLA foi planejada para ser uma força defensiva governamental, com armamentos leves e com o intuito de deter insurgentes nas comunidades designadas (AFRIDI, 2019, p. 32). Sua formação foi idealizada pelos Estados Unidos e seus membros são recrutados localmente pelas comunidades. O principal papel desse contingente é proteger suas províncias de insurgências. Em Uruzgan, os comandantes da PLA foram escolhidos para ocupar seus postos devido a sua associação com as milícias apoiadas pelas forças dos Estados Unidos (SCHMEIDL; MISZAK, 2017, p. 8). Nesse sentido, a PLA era capaz de garantir a segurança da província apenas onde as milícias que os apoiavam possuíam influência 
(SCHMEIDL; MISZAK, 2017, p. 9). Ainda, na província de Nangarhar, o apoio dos Estados Unidos à elite local para comandar a PLA resultou em um desequilíbrio na balança de poder da região, exacerbando a competição política e a fragmentação do governo local. Devido a esse cenário, a comunidade local de Nangarhar passou a compreender a PLA como uma força não confiável (SCHMEIDL; MISZAK, 2017, p. 10).

Como mencionado, a literatura que observa a construção da paz no Afeganistão a partir de uma perspectiva da paz híbrida coloca um grande foco no aspecto clientelista resultante das interações entre o projeto da paz liberal e os atores locais (LISTER, 2007; SHARAN, 2011; MUNCH; VELT, 2017; BOSE, S.; MOTWAN, 2014; SCHMEIDL; MISZAK, 2017; MEHRAN, 2018). Essa rede clientelista é formada principalmente pelos comandantes paramilitares, que detém o controle de suas províncias, e o governo central, que deseja deter o monopólio coercitivo da força e a legitimidade nessas províncias. O papel dos comandantes paramilitares está relacionado com o apontamento desses comandantes dentro de cargos governamentais na reconstrução das novas instituições políticas afegãs pós-2001 (MUKHOPADHYAY, 2009, p. 2).

A perspectiva da paz híbrida sobre a segurança no Afeganistão nos permite observar os limites dos poderes dos atores externos e internos, uma vez que nenhum dos atores conseguiu impor sua visão sobre o monopólico coercitivo estatal. O que emergiu entre as normas liberais de construção da paz e a cooptação de milícias paraestatais é um produto entre acordos e negociações entre ideias e práticas internacionais e locais (MAC GINTY, 2011, p. 106). Além da questão do cooptação de paramilitares, o caso do Afeganistão é emblemático para o estudo das relações híbridas porque as categorias sobre o que é externo e o que é local se mesclam.

\section{CONSIDERAÇÕES FINAIS}

O presente artigo buscou compreender o processo da construção da paz no Afeganistão a partir do conceito da paz híbrida, focando na interação entre atores internacionais, precisamente Estados Unidos, Nações Unidas e OTAN, e atores que representam a elite política afegã. A perspectiva da paz híbrida permitiu um entendimento das dinâmicas que formam a relação entre atores locais e suas diferentes ações em relação ao projeto de construção da paz. Nesse sentido, foi possível delinear algumas das maneiras em que os atores internacionais buscaram impor o projeto de paz liberal no país e também demonstrar como os atores locais apresentam alternativas a essa agenda. 
A partir dessa análise, é possível criticar como os atores internacionais operacionalizaram os atores locais na condução da construção da paz. Isso porque, a construção da paz internacional limitou sua interação com a elites políticas locais cujos interesses não refletem as necessidades da população afegã como um todo.

\section{REFERÊNCIAS}

AFEGANISTÃO. Pacto do Afeganistão. The London Conference on Afghanistan, 31 jan 2006. Disponível em: < https://www.nato.int/isaf/docu/epub/pdf/afghanistan_compact.pdf > Acesso em: 9 mar 2020.

AFRIDI, Ibrahim Sakhi. Creating and recreating security: exploring the hybrid security sector reform in Afghanistan, and its creation of local forces. 2019. Dissertação de Mestrado. Norwegian University of Life Sciences.

AMAN, Shahida. State Failure and State Building in Post Conflict Societies: A Case Study of Afghanistan. 2013. PhD Thesis. UNIVERSITY OF PESHAWAR.

BOSE, Srinjoy; MOTWANI, Nishank. The Limits of 'Hybrid Governance'in Afghanistan. Strategic Analysis, v. 38, n. 4, p. 416-426, 2014.

CHESTERMAN, Simon. Walking softly in Afghanistan: the future of UN state-building. Survival, v. 44, n. 3, p. 37-45, 2002.

DODGE, Toby. Intervention and dreams of exogenous statebuilding: the application of Liberal Peacebuilding in Afghanistan and Iraq. Review of International Studies, v. 39, n. 5, p. 1189-1212, 2013.

FRITZ, J. E. U.S. Peacebuilding in Afghanistan. Bilateral workshop with the Osaka School of International Public Policy (OSIPP). Washington, D.C: Institute for Foreign Policy Analysis: 1-13 p. 2011.

GAO-05-742. Afghan Reconstruction. Report to Congressional Comitte, 2005. Disponível em: <https://www.gao.gov/assets/250/247264.pdf> Acesso em 16 mar. 2020.

GOMES, Áureo de Toledo. Da paz liberal à virada local: avaliando a literatura crítica sobre peacebuilding. Monções: Revista de Relações Internacionais da UFGD, Dourados, v. 2, n. 3, p. 46-76, 2013.

GOMES, Áureo de Toledo. Hybrid democracy: electoral rules and political competition in Afghanistan. Revista Brasileira de Política Internacional, v. 61, n. 1, p. 1-17, 2018.

JARSTAD, A. K.; OLSSON, L. Hybrid Peace Ownership in Afghanistan: International Perspectives of Who Owns What and When. Global Governance, v. 18, p. 105-119, 2012.

KARLBORG, Lisa. International quest for local legitimacy in Afghanistan: A tower of Babel?. Small Wars \& Insurgencies, v. 24, n. 2, p. 349-369, 2013

KERRY, J. F. Evaluating US Foreign Assistance to Afghanistan. A Majority Staff Report Prepared for the Committee on Foreign Relations United States Senate. Estados Unidos, 2011. 
LEONARDSSON, H.; RUDD, G. The 'local turn' in peacebuilding: a literature review of effective and emancipatory local peacebuilding. Third World Quarterly, v. 36, n. 5, p. 825-839, 2015.

LISTER, Sarah. Understanding State-Building and Local Government in Afghanistan. LSE Crisis States Research Centre Working Paper, n. 14, p. 23, 2007.

LOYN, David. Politics without parties: Afghanistan's long road to democracy. Asian Affairs, v. 50, n. 1, p. 40-59, 2019.

MAC GINTY, R. Hybrid peace: The interaction between top-down and bottom-up peace. Security dialogue, v. 14, n. 4, p. 391-412, 2010.

MAC GINTY, Roger; RICHMOND, Oliver. The fallacy of constructing hybrid political orders: a reappraisal of the hybrid turn in peacebuilding. International Peacekeeping, v. 23, n. 2, p. 219-239, 2016.

MAC GINTY, Roger. International peacebuilding and local resistance: Hybrid forms of peace. Springer, 2011.

MALEY, William. Transition in Afghanistan: Hope, Despair and the Limits of Statebuilding. London: Routledge, 2018.

MASCHIETTO, Roberta Holanda. Consolidação internacional da paz versus percepções locais sobre a paz: encontros e desencontros. Conjuntura Global, v. 5, n. 3, p. 512-536, 2016.

MEHRAN, Weeda. Neopatrimonialism in afghanistan: Former warlords, new democratic bureaucrats? Journal of Peacebuilding and Development, v. 13, n. 2, p. 91-105, 2018.

MUKHOPADHYAY, Dipali. Warlords as bureaucrats: The Afghan experience. Carnegie Papers. Middle East Program, n. 101, 2009.

MÜNCH, Philipp; VEIT, Alex. Intermediaries of Intervention: How Local Power Brokers Shape External Peace- and State-Building in Afghanistan and Congo. International Peacekeeping, v. 25, n. 2, p. 266-292, 2018.

OTAN. ISAF's mission in Afghanistan (2001-2014). 2015. Disponível em: < https://www.nato.int/cps/en/natohq/topics 69366.htm >. Acesso em: 25 jun. 2019

S/2001/1154. Agreement on Provisional Arrangements in Afghanistan Pending the Re- Establishment of Permanent Government Institutions (Bonn Agreement), 2001. Disponível em: <https://www.securitycouncilreport.org/un-documents/document/afgh-s2001-1154.php> Acessado em: 3 jul. 2019.

S/RES/1510. Security Council Resolution, 2003. Disponível em: <https://www.securitycouncilreport.org/undocuments/document/afgh-sres1510.php> Acessado em: 5 jul. 2019

SCHMEIDL, Susanne; MISZAK, Nick. The Afghan Local Police: unpacking a hybrid security arrangement. Third World Thematics: A TWQ Journal, v. 2, n. 4, p. 538-556, 2017.

SHARAN, Timor. The Dynamics of Elite Networks and Patron-Client Relations in Afghanistan. Europe-Asia Studies, v. 63, n. 6, p. 1109-1127, 2011.

SUHRKE, Astri; HARPVIKEN, Kristian Berg; STRAND, Arne. Conflictual peacebuilding: Afghanistan two years after Bonn. Chr. Michelsen Institute, 2004. 
TOLEDO, A.; FACCHINI, J. Da transformação de conflitos à paz híbrida: uma análise das ideias de John Paul Lederach e Roger Mac Ginty. Revista Brasileira de Estudos de Defesa, v. 4, n. 2, 2017.

VAN DER LIJN, J. Frictions in illusionstan: engagement between the 'global'and the 'local'in Afghanistan's imagi-nation-building. In: BJÖRKDAHL, Annika et al. Peacebuilding and Friction. Routledge, 2016. p. 169185.

WARDAK, A.; HAMIDZADA, H. The Search for Legitimate Rule, Justice and a Durable Peace: Hybrid Models of Governance in Afghanistan. Journal of Peacebuilding \& Development, v. 7, n. 2, p. 79-88, 2012. 